\title{
At the moment of occurrence of a fragility hip fracture, men have higher mechanical properties values in comparison with women
}

Ana C Vale $e^{1,2}$, Inês P Aleixo ${ }^{1}$, Miguel Lúcio ${ }^{1,2}$, André Saraiva ${ }^{1,2}$, Joana Caetano-Lopes ${ }^{1}$, Ana Rodrigues ${ }^{1,3}$,
Pedro M Amaral ${ }^{2}$, Luís G Rosa ${ }^{2,4}$, Jacinto Monteiro ${ }^{5}$, João E Fonseca ${ }^{1,3^{*}}$, Maria F Vaz ${ }^{2,4}$ and Helena Canhão ${ }^{1,3}$

\begin{abstract}
Background: It is well established that males have lower fracture risk in comparison with females, which suggests a higher bone resistance in men. The aim of our study was to find out if in older patients with hip fragility fractures, gender has also an impact on trabecular bone material behaviour, specifically to determine whether trabecular mechanical properties under compressive loading differ between men and women who suffered a fragility hip fracture.

Methods: Femoral epiphyses were consecutively collected during hip replacement surgery due to proximal femur fragility fracture. Trabecular bone cylinders were drilled and submitted to uniaxial compression tests and mechanical properties were assessed.

Results: Seventy-three patients, 55 women (mean age 81 years and standard deviation of 7 years) and 18 men (mean age 81 years and standard deviation of 8 years) were evaluated. The ultimate stress of trabecular bone was significantly higher in men than in women: the median values and the interquartile range (IQR) were respectively 8.04(5.35-10.90) MPa vs. 4.46(3.02-7.73) MPa, $(p$-value =0.005). The same difference between male and female was observed in the Young's modulus: 293.68(166.67-538.18) MPa vs. 174.26(73.07-322.28) MPa, ( $p$-value =0.028), and also in the energy to failure: $0.25(0.07-0.42) \mathrm{MJ} / \mathrm{m}^{3}$ vs. $0.11(0.05-0.25) \mathrm{MJ} / \mathrm{m}^{3}$, ( $p$-value $\left.=0.058\right)$. These differences were also verified after adjusting the analysis for age in a multivariate model analysis.
\end{abstract}

Conclusions: Our observations demonstrated that, even in a population who suffered a fragility hip fracture, men still have higher trabecular bone mechanical properties in comparison with women.

Keywords: Trabecular bone, Osteoporosis, Fragility fracture, Compression, Mechanical properties

\section{Background}

Osteoporosis is a systemic skeletal disease characterized by low bone mass, microarchitectural deterioration and strength impairment, which increase the risk of fragility fractures, leading to high morbidity and reducing patient's quality of life [1-7]. Bone loss is clinically evaluated by bone mineral density (BMD), but low BMD only explains a minority of the fractures that occur $[2,8-10]$, since bone

\footnotetext{
* Correspondence: jefonseca@netcabo.pt

'Rheumatology Research Unit, Instituto de Medicina Molecular, Faculdade de Medicina da Universidade de Lisboa, Lisbon, Portugal

${ }^{3}$ Serviço de Reumatologia e Doenças Ósseas Metabólicas, Lisbon Academic Medical Centre, Lisbon, Portugal

Full list of author information is available at the end of the article
}

structure, microarchitecture and material properties also account for bone fragility.

Gender and age influence the risk of fracture [2,11-19]. The peak number of hip fractures occurs at 75-79 years of age for both sexes [11]. However, the hip fracture risk increases in women after 40 years and in male, increases only after 65 years [11]. Moreover, about $70 \%$ of all hip fractures occur in women [20]. This might be explained by several factors. On one hand, changes in bone structure and geometry induced by aging contribute to decreased bone strength and increased fragility fracture risk in the elderly population $[12,13,16,18,21,22]$. On the other hand, important determinants of bone strength are clearly different between genders. In fact, when peak bone mass is

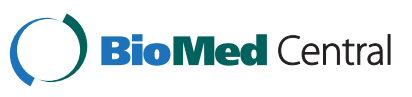


achieved, bone density in men is one fourth to one third greater than in women [15] and male bones reach a larger diameter and cortical thickness than female ones $[15,18]$. Additionally, the pattern of bone loss is different between genders [15]. Bone mass rapidly decreases in women at menopause, around 50 years-old, [18] in contrast with men of the same age. Consequently, differences between genders get more pronounced with aging [12-19]. Another gender difference is related to bone loss at a microstructural level, which occurs mainly by trabecular thinning and reduced bone formation in men and mainly by loss of connectivity between trabeculae in women $[1,15,18]$.

Beyond age and sex, the mechanical properties of bone depend on several factors, such as density and the distribution of bone mass [23-27], geometry [23,27], microarchitecture [28,29], bone composition [8,18,24,30-33], anatomical location [34-36] and concomitant diseases [28,31,32,37-39].

As most fractures at hip, vertebrae or wrist tend to start in the trabecular (cancellous) bone, with a decrease of bone mass and microarchitectural changes, an understanding of the mechanical properties of trabecular bone is extremely important in the evaluation of the risk of fracture [40,41]. Results of tensile and bending tests performed in young, middle-aged, and elderly patients showed that aging significantly decreases cancellous bone strength [42]. However, to our knowledge, there are no studies with compressive tests on trabecular bone that had investigated the effect of both gender and age, performed in an elderly population who had suffered a hip fragility fracture. It is unknown whether trabecular bone of patients who suffered a fragility fracture differs between women and men.

Moreover, given the differences in bone behaviour observed between men and women in other settings, we hypothesized that elderly men who suffered a fragility fracture have different mechanical properties than women. Thus, the aim of this study was to assess and compare the trabecular bone compression behaviour in elderly men and women who suffered a hip fragility fracture.

\section{Methods}

\section{Patients}

Patients who suffered a low-energy hip fracture and underwent total hip replacement surgery at the Orthopedic Department of Hospital de Santa Maria were consecutively recruited for this study from 2007 up to 2009. Demographic and clinical data such as age, gender and surgery reason were collected. Patients with other metabolic bone diseases and bone metastases were excluded. Seventy-three femoral epiphyses from patients submitted to total hip replacement surgery (fifty-five women and eighteen men) due to low-energy fracture were consecutively collected. The mean age of both genders was
81 years-old, where the age range for females from 59 to 96 years-old (standard deviation of 7 years) and for males from 64 to 84 years-old (standard deviation of 8 years). Three age-groups were defined: below 75 yearsold ( 8 females, 4 males), 75 to 85 years-old ( 29 females, 11 males) and over 85 years-old (18 females, 3 males).

Written informed consent was obtained from all patients and the study was conducted in accordance with the regulations governing clinical trials, such as the Declaration of Helsinki, as amended in Seoul (2008), and was approved by the Ethical Committee of the Lisbon Academic Medical Centre, Portugal.

\section{Specimen preparation}

After the surgical procedure, the femoral epiphyses were immediately stored at $-80^{\circ} \mathrm{C}$. Before testing, this material was defrosted at room temperature.

We used a perforating drill with a diameter of $15 \mathrm{~mm}$ and a length: diameter ratio of 2 , with a corresponding final specimen length of $30 \mathrm{~mm}$. The trabecular bone cylinders were obtained by drilling in the highest in vivo loading direction, in accordance with Sun et al. [38]. The cortical shell was cut off.

The cylinders' ends were polished with an 800 grade silicon carbide paper under water flow (Surface Polishing Machine Struers DAP-V) to make them parallel. Bone cylinders were de-fatted for three hours using a chloroform and methanol solution (1:1 ratio) and were hydrated overnight in phosphate-buffered saline (PBS) solution.

\section{Compression tests}

Uniaxial compression tests were performed in a universal testing machine (model 5566, Instron Corporation, Canton, USA), with a load cell of $10 \mathrm{kN}$ and a cross-head rate of $0.1 \mathrm{~mm} / \mathrm{s}$ that was chosen in accordance with $\mathrm{Li}$ and Aspen [31]. All samples were loaded in the principal stress direction (superior-inferior direction). The testing machine was operated by materials testing software (Bluehill2, Instron Corporation, Canton, USA).

Stress-strain $(\sigma-\varepsilon)$ curves were obtained for each specimen from the load $(\mathrm{F})$ vs. displacement $(\Delta \mathrm{L})$ data acquired, taking into consideration the dimensions of the specimens, area (A) and length ( $\mathrm{L}$ ), with diameter and height measured three times. The stress, $\sigma$, is defined as the load divided by the area, $\sigma=\mathrm{F} / \mathrm{A}$, while the strain, $\varepsilon$, is the ratio $\varepsilon=\Delta \mathrm{L} / \mathrm{L}$. Three mechanical parameters were obtained from the stress-strain curve: Young's modulus, E (calculated as the slope of the stress-strain curve in the linear elastic region), ultimate stress, $\sigma_{\mathrm{ULT}}$ (the maximum stress that the bone can support without failing), and energy to failure, $\mathrm{W}_{\mathrm{ULT}}$ (measured by the area under the stress-strain curve until the ultimate stress). The mechanical parameters Young's modulus, ultimate stress and the energy to failure, were used to evaluate mecha- 
nical properties, respectively stiffness, mechanical strength and toughness.

\section{Statistical analysis}

Statistical analysis was performed using a statistical software (version 9.2, SAS Institute Inc., Cary, NC, USA). The Shapiro Wilk test indicated that the continuous outcome variables (Young's modulus, ultimate stress and energy to failure) had non-normal distributions. Therefore, non-parametric tests were used for statistical analysis and the data were presented as median and interquartile range (Q1-Q3). More specifically, the nonparametric tests, Mann-Whitney and the Kruskal-Wallis tests, were performed to assess comparisons between two (female and male population) and three groups (the three age-groups defined), respectively.

Firstly, with the entire sample, a univariate comparison between female and male was made for each property, using the Mann-Whitney test. In addition, a univariate comparison for determination of age-group differences for each material parameter, using the Kruskal-Wallis test, was done for the entire population. Also, the univariate correlation, given by the Spearman's correlation coefficient of age as a continuous variable for each material measure, was performed for males and females separately.

Finally, the contribution of the independent variables (gender and age-groups, and gender and age as a continuous variable) on the prediction of each bone mechanical property was determined by two multivariate quartile (median) regression models. Quartile (median) regression consists of a newly developed transformed multivariate linear regression analysis for non-normal outcomes (SAS software, version 9.2).

Differences were considered statistically significant between groups for two-sided p-value lower than 0.05 .

\section{Results}

A typical stress-strain curve from female and male patients is exemplified in Figure 1a), where the determination of important parameters, E, $\sigma_{\mathrm{ULT}}$ and $\mathrm{W}_{\mathrm{ULT}}$ are indicated. Figure 1b) exhibits six stress-strain curves, for male and female, belonging to the three age-groups considered.

For the overall sample data, when comparing female, $\mathrm{F}$, and male, $\mathrm{M}$, (Table 1), significant differences between genders were detected in bone material parameters $\left(\mathrm{E}, \sigma_{\mathrm{ULT}}\right.$ and $\left.\mathrm{W}_{\mathrm{ULT}}\right)$. The ultimate stress that evaluates the mechanical strength was the mechanical parameter that exhibited more significant differences $(p=0.005)$. The Young's modulus, which is related to stiffness, also presented significant differences between male and female $(p=0.028)$. In contrast, the energy to failure (i.e. a measure of the toughness) was not significantly different ( $\mathrm{p}=$
0.058), but male values tended to be higher than female ones.

The Young's modulus, E, and the energy to failure, $\mathrm{W}_{\text {ULT }}$, exhibited statistically significant differences on age-group comparison, regardless of gender (Table 2). However, only $W_{U L T}$ increased continuously with aging. The average ultimate stress did not change significantly with age, while the Young's modulus was lower in the oldest group.

Using age as a continuous variable (Figure 2), again like for age-group analysis, the energy to failure, $\mathrm{W}_{\mathrm{ULT}}$, was the mechanical parameter that exhibited the highest and the most significant Spearman's correlation coefficient $(\rho)$ in association with age for both genders (for males, $\rho=0.485, p$-value $=0.035$, and for females, $\rho=0.316$, $p$-value $=0.017)$. Moreover, the energy to failure increases with aging, for both genders, while the ultimate stress, presents a positive Spearman's correlation coefficient, but with no statistical significance. In contrast, the Young's modulus decreases with age, but no statistical significance was found.

Two multivariate (bivariate) quartile regression analysis models were performed taking each bone mechanical parameter as the outcome (Table 3): one model had age (as a continuous variable) and gender as covariates, while the other one considered gender and age-group (as a categorical variable) as covariates. This bivariate median regression analysis showed significant differences only in energy to failure, for models that combined agegroup and gender ( $p$-value of 0.02 and 0.04 , respectively). Age was also a significant predictor of energy to failure, since with the first bivariate model, with age and gender, the energy to failure presented a beta coefficient with a significant difference $(\mathrm{p}=0.01)$. All the other parameters, $\mathrm{E}$ and $\sigma_{\mathrm{ULT}}$, showed no significant differences for both bivariate median regression models, which suggests that age and gender effects can be confounded in Young's modulus and ultimate stress prediction by the bivariate models used.

\section{Discussion}

Our results showed a significant difference in bone mechanical strength, estimated by the ultimate stress, between elderly men and women (mean age of 81 years-old for both genders) who had experienced a hip fragility fracture.

The Young's modulus, the ultimate stress and the energy to failure were higher in elderly men than in women, which is in accordance with previous studies that qualitatively predicted lower material properties in women when compared to men [22]. Also one could speculate that male hip fractures occur at higher energy levels [11]. The values obtained in the present work for the mechanical parameters are in agreement with other figures previously published, both in terms of absolute and relative values [31]. 

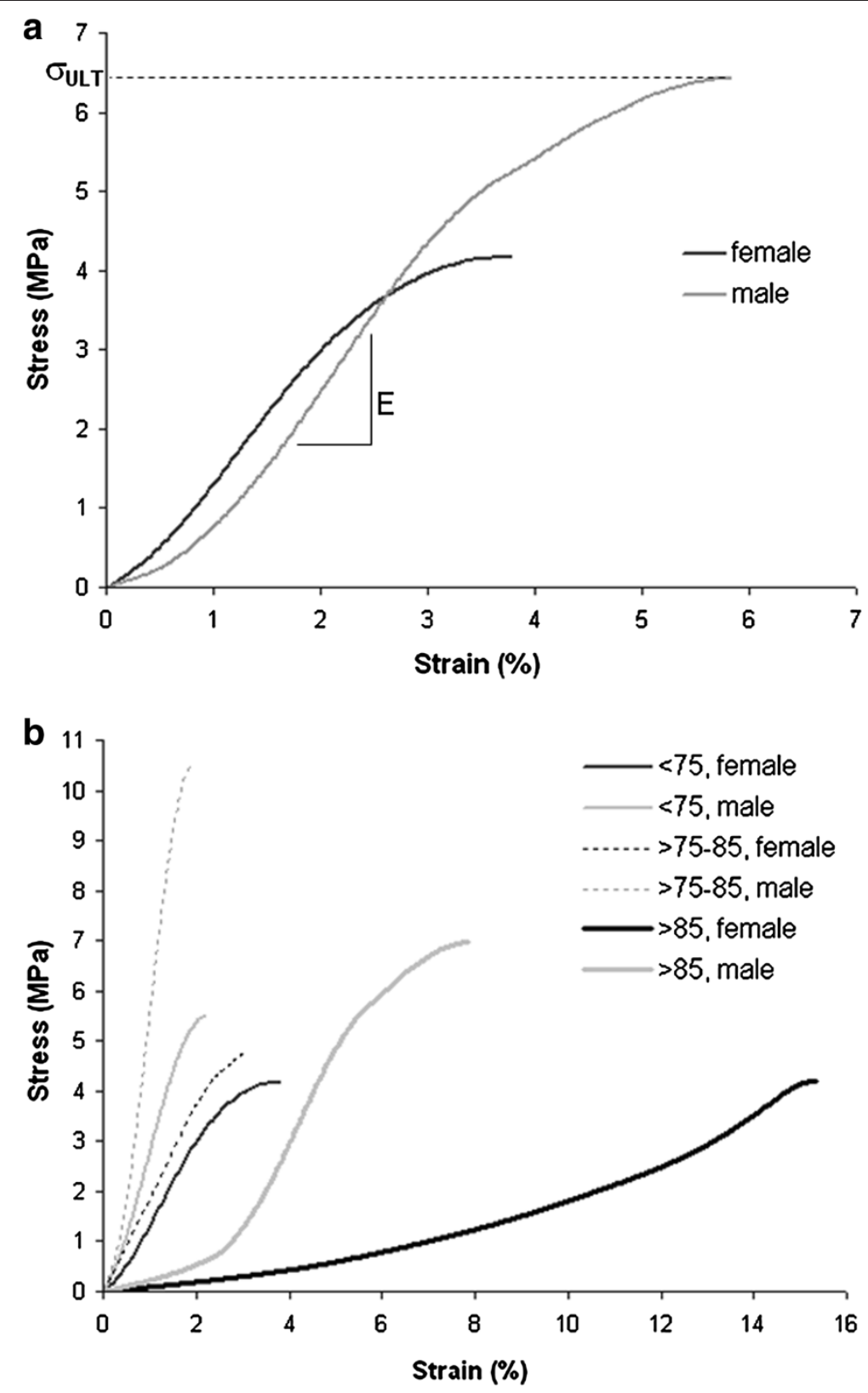

Figure 1 Experimental compressive stress-strain curves. a) from female and male fracture: the parameters ultimate stress, $\sigma_{U L T}, Y^{\prime}$ Young's modulus, $E$, are indicated. The energy to failure, $W_{U L T}$, corresponds to the area below the stress-strain curve. $\mathbf{b}$ ) six stress-strain curves for male and female belonging to the three considered age-groups. Each curve represented corresponds to the experimental curve with ultimate stress value closest to the median value corresponding to each age-group.

Table 1 Summary of mechanical parameters by gender: median (IQR)

\begin{tabular}{cccc}
\hline Measure & Female $(\boldsymbol{N}=\mathbf{5 5})$ & Male $(\boldsymbol{N}=\mathbf{1 8})$ & $\boldsymbol{p}_{\text {-value }}$ \\
\hline Age $[\mathrm{years}]$ & $82(77-86)$ & $81(78-84)$ & 0.605 \\
Ultimate stress, $\boldsymbol{\sigma}_{\mathrm{ULt}}[\mathrm{MPa}]$ & $4.46(3.02-7.73)$ & $8.04(5.35-10.90)$ & 0.005 \\
Young's modulus, $\mathrm{E}[\mathrm{MPa}]$ & $174.26(73.07-322.28)$ & $293.68(166.67-538.18)$ & 0.028 \\
Energy to failure, $\mathbf{W}_{\mathrm{ULT}}\left[\mathrm{MJ} / \mathrm{m}^{3}\right]$ & $0.11(0.05-0.25)$ & $0.25(0.07-0.42)$ & 0.058 \\
\hline
\end{tabular}

Note: IQR = Interquartile range.

${ }^{a} p$-value obtained by Mann-Whitney test for univariate comparison between female and male, with statistical significance for $p<0.05$. 
Table 2 Summary of mechanical parameters by age-group: median (IQR)

\begin{tabular}{|c|c|c|c|c|}
\hline Measure & $<75(N=12)$ & $\geq 75-85>(N=40)$ & $\geq 85(N=21)$ & $p$-value ${ }^{a}$ \\
\hline Age [years] & $70(66-71)$ & $81(78-83)$ & $88(86-93)$ & $<.0001$ \\
\hline Ultimate stress, $\sigma_{\mathrm{ULT}}[\mathrm{MPa}]$ & $4.49(3.85-5.34)$ & $7.03(3.45-10.99)$ & $5.30(3.69-6.96)$ & 0.163 \\
\hline Young's modulus, E [MPa] & $238.23(129.77-328.50)$ & $244.98(115.96-516.13)$ & $87.72(29.76-251.70)$ & 0.037 \\
\hline Energy to failure, $\mathrm{W}_{\mathrm{ULT}}\left[\mathrm{MJ} / \mathrm{m}^{3}\right]$ & $0.06(0.06-0.09)$ & $0.16(0.05-0.27)$ & $0.249(0.10-0.40)$ & 0.037 \\
\hline
\end{tabular}

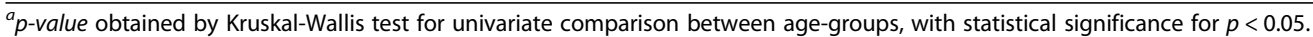

The only exception was observed in energy to failure that was slightly lower in male patients as compared to females in the younger age group (less than 75 years-old). Li and Aspen [31] found for the Young's modulus of the osteoporotic bone $\mathrm{E}=247 \mathrm{MPa}$, while Wang et al. [42] found that average values of the Young's modulus, obtained by bending tests in different age-groups, decreased with aging and showed values of 209, 207 and $143 \mathrm{MPa}$, respectively for young, middle age and elderly patients.

Regarding age effects, a decrease in the Young's modulus and an increase in the energy to failure were detected, while the ultimate stress was almost constant. These results are unexpected, as for example, Wang et al. [42] report that age-dependent changes are reflected in a decreased strength, elastic modulus and work to fracture. However, our age interval is considerably narrow which may have biased that effect.

For the three defined age-groups similar gender differences on each parameter determined were noted and this fact might reveal that the age-related bone degradation can affect both genders in the same way. However, for the oldest age-group, gender-related differences were not detected, probably because, in this context, the gender-effect might be overcame by the impact of age.

There are some limitations in this study that should be taken into account. Firstly, conclusions are only valid for trabecular bone. However, most of the fractures start to occur at the trabecular zones of bones $[28,37,43]$ and thus trabecular fragility can be regarded as a strong suggestive indication of overall bone fragility. In addition to this limitation, there was an imbalance in the proportion of females and males within each age-group, particularly in the case of the general age-group comparison. The reason for this fact is that study's population includes consecutive human samples obtained from hip replacement surgeries due to hip fracture, a condition that occurs late in life, the age range of the patients was narrow and skewed to older age. Additionally, because this is a con-

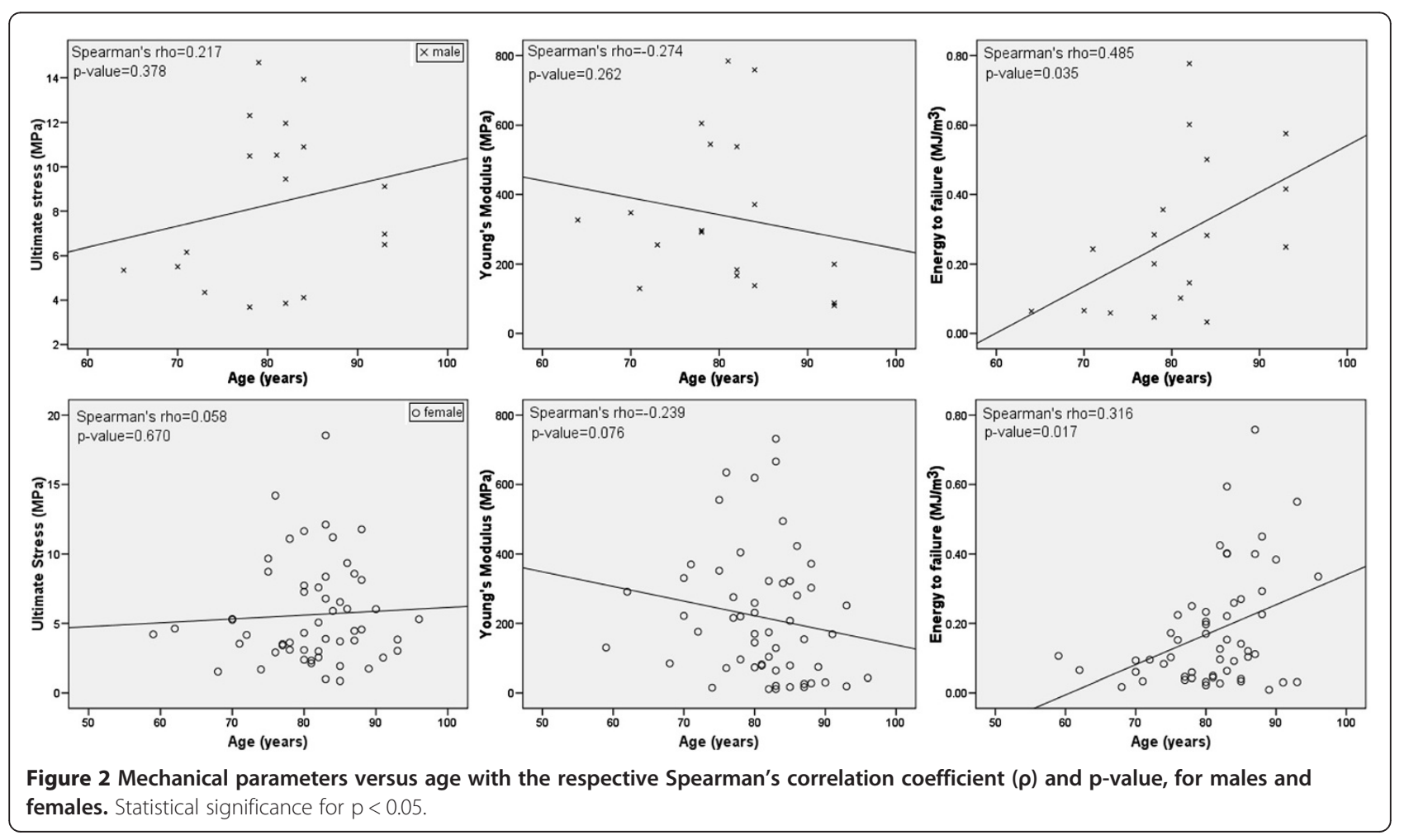


Table 3 Multiple median regression analysis for bone material properties

\begin{tabular}{|c|c|c|c|c|c|c|}
\hline Variables & & Age & & & Gender & \\
\hline Measure & $\beta^{a}$ & 95\% Confidence Interval & $p$-value ${ }^{b}$ & $\beta^{a}$ & 95\% Confidence Interval & $p$-value \\
\hline Ultimate stress, $\sigma_{\mathrm{ULT}}[\mathrm{MPa}]$ & 0.02 & $-0.11<\boldsymbol{\beta}<0.16$ & 0.72 & -2.29 & $-5.43<\boldsymbol{\beta}<0.86$ & 0.15 \\
\hline Young's modulus, E [MPa] & -6.10 & $-12.54<\boldsymbol{\beta}<0.34$ & 0.06 & -97.72 & $-216.06<\boldsymbol{\beta}<20.62$ & 0.10 \\
\hline Energy to failure, $\mathrm{W}_{\mathrm{ULT}}\left[\mathrm{MJ} / \mathrm{m}^{3}\right]$ & 0.01 & $0.00<\boldsymbol{\beta}<0.02$ & 0.01 & -0.09 & $-0.22<\boldsymbol{\beta}<0.03$ & 0.13 \\
\hline Variables & & Age-group & & & Gender & \\
\hline Ultimate stress, $\sigma_{\mathrm{ULT}}[\mathrm{MPa}]$ & 0.57 & $-0.68<\boldsymbol{\beta}<1.81$ & 0.37 & -2.00 & $-5.27<\boldsymbol{\beta}<1.27$ & 0.23 \\
\hline Young's modulus, E [MPa] & -34.89 & $-124.20<\boldsymbol{\beta}<54.42$ & 0.44 & -104.49 & $-238.15<\boldsymbol{\beta}<29.17$ & 0.12 \\
\hline Energy to failure, $\mathrm{W}_{\mathrm{ULT}}\left[\mathrm{MJ} / \mathrm{m}^{3}\right]$ & 0.09 & $0.02<\boldsymbol{\beta}<0.16$ & 0.02 & -0.13 & $-0.25<\boldsymbol{\beta}<-0.01$ & 0.04 \\
\hline
\end{tabular}

${ }^{a}$ Coefficients obtained by QUANTREG procedure.

${ }^{b}$ Statistical significance $p<0.05$.

Note: Two multiple median regression models were performed. In the first model, each bone material property (the dependent variable) was analysed with age and gender as covariate variables. In the second model, these bone material parameters were analysed with age-group and gender as covariate variables.

dition that occurs more frequently in women, the number of females was also higher. Therefore, the conclusions obtained in the present work have limitations in their extrapolation out of this specific population.

There are several bone microstructural aspects to help to understand the biomechanical results obtained in this study. The microstructure of trabecular bone exhibit age- and gender-related variations [44-46]. Micro-CT may be used to evaluate differences of trabecular microstructure, for example between several age groups [45] at different bone regions. The bone volume fraction decreases with age for both women and men [44,45]. However, for the same age group, the bone volume fraction is higher in men when compared to women [44]. The trabecular thickness also decreases with aging [46]. Besides age and gender, the disease also affects the properties of a single trabeculae. For example, osteoporotic trabeculae showed decreases in Young's modulus, yield strength and work to failure [47].

Being bone a nanocomposite material consisting of mineral crystals and organic phase, bone strength also depends on its intrinsic material properties [43,48,49]. In fact, elderly women displayed large mineral grains, while small grains indicate the presence of younger bone with a more recently remodelled structure [49]. On the other hand, it is believed that the organic phase contributes to age differences in elasticity, explaining a lower elastic behaviour of elderly bone trabeculae [48]. It was also found that in young trabeculae, the arrangement of the matrix provide an increase of the interface available for cracking between the mineralized fibrils, which may reduce crack propagation and will help to dissipate a large amount of energy [49].

Studies that combine mechanical and microstructural tests showed that there are different relationships between mechanics and structure $[28,50]$. For osteoporotic samples a decrease on the bone volume fraction is followed by a decrease in the elastic modulus and mechanical strength
[50]. It is also known that lower bone volume fraction, lower trabecular number and decreased connectivity are important determinants of hip fracture [28].

\section{Conclusions}

This study reported gender differences in the mechanical properties of trabecular femoral bone of elderly patients who suffered a hip fragility fracture. Based on this population, male trabecular bone showed higher mechanical properties: a higher value of Young's modulus and ultimate stress when compared to women. Furthermore, the deterioration of bone properties affected more dramatically the Young's modulus, especially in the oldest patients.

\section{Competing interests}

The authors declare that they have no competing interests.

\section{Authors' contributions}

ACV acquired and interpreted the experimental data, performed the statistical analysis and drafted the manuscript. IPA, ML and AS made essential contributions for sample preparation and made the experimental tests. JCL and AR participated in sample collection and selected the most suitable samples. JM was the surgeon responsible for the hip replacement surgeries. PMA and LGR contributed for the optimization of the experimental methodology. JEF made substantial contributions in sample selection, in data analysis, drafting and revising the article for important intellectual content. MFV made essential contributions in design of the experimental methodology, in data interpretation, and in drafting the manuscript and in revising. $\mathrm{HC}$ made substantial contributions for interpretation of data and in statistical analysis, and was involved in revising the manuscript critically. All authors read and approved the final manuscript.

\section{Acknowledgements}

AC Vale thanks the Portuguese research foundation FCT, "Fundação para a Ciência e Tecnologia", for the Ph.D. grant SFRH/BD/48100/2008.

\section{Author details}

${ }^{1}$ Rheumatology Research Unit, Instituto de Medicina Molecular, Faculdade de Medicina da Universidade de Lisboa, Lisbon, Portugal. ${ }^{2}$ Instituto de Ciência e Engenharia de Materiais e Superfícies, Instituto Superior Técnico, University of Lisbon, Av. Rovisco Pais, Lisbon, Portugal. ${ }^{3}$ Serviço de Reumatologia e Doenças Ósseas Metabólicas, Lisbon Academic Medical Centre, Lisbon, Portugal. ${ }^{4}$ Departamento de Engenharia Mecânica, Instituto Superior Técnico, UL, Av. Rovisco Pais, Lisbon, Portugal. ${ }^{5}$ Serviço de Ortopedia, Hospital de Santa Maria, Lisbon, Portugal. 
Received: 30 April 2012 Accepted: 1 October 2013

Published: 16 October 2013

\section{References}

1. Gagnon C, Li V, Ebeling PR: Osteoporosis in men: its pathophysiology and the role of teriparatide in its treatment. Clin Interv Aging 2008, 3:635-645

2. Geusens $P$, Dinant G: Integrating a gender dimension into osteoporosis and fracture risk research. Gend Med 2007, 4:147-161.

3. Giangregorio L, Dolovich L, Cranney A, et al: Osteoporosis risk perceptions among patients who have sustained a fragility fracture. Patient. Edu. Couns. 2009, 74:213-220.

4. Gregory JS, Aspden RM: Femoral geometry as a risk factor for osteoporotic hip fracture in men and women. Med Eng Phys 2008, 30:1275-1286.

5. Raisz LG: Pathogenesis of osteoporosis: concepts, conflicts, and prospects. J Clin Invest 2005, 115:3318-3325.

6. Saag KG, Geusens P: Progress in osteoporosis and fracture prevention: focus on postmenopausal women. Arthritis Res Ther 2009, 11:1-18.

7. van Helden S, van Geel AC, Geusens PP, et al: Bone and fall-related fracture risks in women and men with a recent clinical fracture. J Bone Joint Surg Am 2008, 90:241-248.

8. Hernandez CJ, Keaveny TM: A biomechanical perspective on bone quality. Bone 2006, 39:1173-1181.

9. Thomas CD, Mayhew PM, Power J, et al: Femoral neck trabecular bone: loss with aging and role in preventing fracture. J Bone Miner Res 2009, 24:1808-1818.

10. Weinans $\mathrm{H}$ : Architectural changes independent of bone mineral in osteoporosis. J. Musculoskel. Neuron Interact. 2002, 2:535-537.

11. Johnell O, Kanis JA: An estimate of the worldwide prevalence and disability associated with osteoporotic fractures. Osteoporos Int 2006, 17:1726.

12. Bouxsein ML, Melton $L$, Riggs BL, et al: Age- and sex-specific differences in the factor of risk for vertebral fracture: a population-based study using QCT. J Bone Miner Res 2006, 21:1475-1482

13. Duan Y, Beck TJ, Wang X-F, Seeman E: Structural and biomechanical basis of sexual dimorphism in femoral neck fragility has its origins in growth and aging. J Bone Miner Res 2003, 18:1766-1774.

14. Hudelmaier M, Kollstedt A, Lochmüller EM, et al: Gender differences in trabecular bone architecture of the distal radius assessed with magnetic resonance imaging and implications for mechanical competence. Osteoporos Int 2005, 16:1124-1133.

15. Seeman E: The structural basis of bone fragility in men. Bone 1999 25:143-147.

16. Seeman E: During aging, men lose less bone than women because they gain more periosteal bone, not because they resorb less endosteal bone. Calcif Tissue Int 2001, 69:205-208.

17. Seeman E: The structural and biomechanical basis of the gain and loss of bone strength in women and men. Endocrinol Metab Clin North Am 2003, 32:25-38.

18. Seeman E: Bone's material and structural strength. Curr Opin Orthop 2007, 18:494-498.

19. Zhang F, Tan L-J, Lei S-F, Deng H-W: The differences of femoral neck geometric parameters: effects of age, gender and race. Osteoporos Int 2010, 21:1205-1214.

20. Jordan KM, Cooper C: Epidemiology of osteoporosis. Best Pract Res Clin Rheumatol 2002, 16:795-806.

21. Seeman E: Structural basis of growth-related gain and age-related loss of bone strength. Bone 2008, 47:2-8.

22. Wang $X-F$, Duan $Y$, Beck TJ, Seeman E: Varying contributions of growth and ageing to racial and sex differences in femoral neck structure and strength in old age. Bone 2005, 36:978-986.

23. Ammann P, Rizzoli R: Bone strength and its determinants. Osteoporos Int 2003, 14:13-18.

24. Cory E, Nazarian A, Entezari V, Vartanians V, Müller R, Snyder BD: Compressive axial mechanical properties of rat bone as functions of bone volume fraction, apparent density and micro-CT based mineral density. J Biomechanics 2010, 43:953-960.

25. Kopperdahl DL, Keaveny TM: Yield strain behavior of trabecular bone. J Biomechanics 1998, 31:601-608.

26. Mueller TL, van Lenthe GH, Stauber M, Gratzke C: Regional, age and gender differences in architectural measures of bone quality and their correlation to bone mechanical competence in the human radius of an elderly population. Bone 2009, 45:882-891.

27. Silva MJ: Biomechanics of osteoporotic fractures. Injury 2007, 38:69-76.

28. Ciarelli TE, Fyhrie DP, Schaffler MB, Goldstein SA: Variations in three-dimensional cancellous bone architecture of the proximal femur in female hip fractures and in controls. J Bone Miner Res 2000, 15:32-40.

29. Goldstein SA, Goulet R, McCubbrey D: Measurement and significance of three-dimensional architecture to the mechanical integrity of trabecular bone. Calcif Tissue Int 1993, 53:127-132.

30. Bayraktar HH, Keaveny TM: Mechanisms of uniformity of yield strains for trabecular bone. J Biomech 2004, 37:1671-1678.

31. Li B, Aspden RM: Composition and mechanical properties of cancellous bone from the femoral head of patients with osteoporosis or osteoarthritis. J Bone Miner Res 1997, 12:641-651.

32. Caetano-Lopes J, Nery AM, Henriques R, Canhão H, Duarte J, Amaral PM, Moura RA, Pereira PA, Weinmann P, Abdulghani S, Souto-Carneiro M, Rego P, Monteiro J, Sakagushi S, Queiroz MV, Konttinen YT, Graça L, Vaz MF, Fonseca JE: Chronic arthritis directly induces quantitative and qualitative bone disturbances leading to compromised biomechanical properties. Clin Exp Rheumatol 2009, 27:475-482

33. van der Linden JC, Birkenhäger-Frenkel DH, Verhaar JA, Weinans $H$ : Trabecular bone's mechanical properties are affected by its non-uniform mineral distribution. J Biomech 2001, 34:1573-1580.

34. Morgan EF, Keaveny TN: Dependence of yield strain of trabecular bone on anatomic site. J Biomech 2001, 34:569-577.

35. Morgan EF, Bayraktar HH, Keaveny TM: Trabecular bone modulus-density relationship depends on anatomic site. J Biomech 2003, 36:897-904.

36. Nazarian A, Muller J, Zurakowski D, Müller R, Snyder BD: Densitometric, morphometric and mechanical distributions in the human proximal femur. J Biomech 2007, 40:2573-2579.

37. Homminga J, McCreadie BR, Ciarelli TE, Weinans H, Goldstein SA, Huiskes R: Cancellous bone mechanical properties from normals and patients with hip differ on the structure level not on the bone hard tissue level. Bone 2002, 30:759-764.

38. Sun S-S, Ma H-L, Liu C-L, Huang CH, Cheng CK, Wei HW: Difference in femoral head and neck material properties between osteoarthritis and osteoporosis. Clin Biomech 2008, 23:39-47.

39. Woo DG, Kim CH, Lim D, Kim HS: Experimental and simulated studies on the plastic mechanical characteristics of osteoporotic vertebral trabecular bone. Curr Appl Phys 2010, 10:729-733.

40. Fratzl P, Weinkamer R: Nature's hierarchical materials. Prog Mater Sci 2007, 52:1263-1334

41. Gibson L, Ashby M (Eds): Cellular Solids, Structure and Properties. Cambridge UK: Cambridge University Press; 1999.

42. Wang X, Shen X, Li X, Mauli Agrawal C: Age-related changes in the collagen network and toughness of bone. Bone 2002, 31:1-7.

43. Fratzl-Zelman N, Roschger P, Gourrier A, Weber M, Misof BM, Loveridge N, Reeve J, Klaushofer K, Fratzl P: Combination of nanoindentation and quantitative backscattered electron imaging revealed altered bone material properties associated with femoral neck fragility. Calcif Tissue Int 2009, 85:335-43.

44. Chen H, Zhou X, Shoumura S, Emura S, Bunai Y: Age- and gender-dependent changes in three-dimensional microstructure of cortical and trabecular bone at the human femoral neck. Osteoporos Int 2010, 21:627-636.

45. Djuric M, Djonic D, Milovanovic P, Nikolic S, Marshall R, Marinkovic J, Hahn $M$ : Region-specific sex-dependent pattern of age-related changes of proximal femoral cancellous bone and its implications on differential bone fragility. Calcif Tissue Int 2010, 86:192-201.

46. Cui W-Q, Won Y-Y, Baek M-H, Lee D-H, Chung Y-S, Hur J-H, Ma Y-Z: Age-and region-dependent changes in three-dimensional microstructural properties of proximal femoral trabeculae. Osteoporos Int 2008, 19:1579-1587.

47. Busse B, Hahn M, Soltau M, Zustin J, Püschel K, Duda GN, Amling M: Increased calcium content and inhomogeneity of mineralization render bone toughness in osteoporosis: mineralization, morphology and biomechanics of human single trabeculae. Bone 2009, 45:1034-1043.

48. Milovanovic P, Potocnik J, Djonic D, Nikolic S, Zivkovic V Djuric M, Rakocevic Z. Age-related deterioration in trabecular bone mechanical properties at material level: nanoindentation study of the femoral neck in women by using AFM. Exp Gerontol 2012, 47:154-159

49. Milovanovic P, Djuric M, Rakocevic Z: Age-dependence of power spectral density and fractal dimension of bone mineralized matrix in atomic 
force microscope topography images: potential correlates of bone tissue age and bone fragility in female femoral neck trabeculae. J Anat 2012, 221:427-33.

50. Vale AC, Pereira MFC, Maurício A, Amaral P, Rosa LG, Lopes A, Rodrigues A, Caetano-Lopes J, Vidal B, Monteiro J, Fonseca JE, Canhão H, Vaz MF: Micro-computed tomography and compressive characterization of trabecular bone. Colloids and Surfaces A: Physicochemical and Engineering Aspects-In Press, Corrected Proof; 2013. http://dx.doi.org/10.1016/j.colsurfa.2013.01.057.

doi:10.1186/1471-2474-14-295

Cite this article as: Vale et al:: At the moment of occurrence of a fragility hip fracture, men have higher mechanical properties values in

comparison with women. BMC Musculoskeletal Disorders 2013 14:295.

\section{Submit your next manuscript to BioMed Central and take full advantage of:}

- Convenient online submission

- Thorough peer review

- No space constraints or color figure charges

- Immediate publication on acceptance

- Inclusion in PubMed, CAS, Scopus and Google Scholar

- Research which is freely available for redistribution 